Summer 6-1-2008

\title{
Endovascular Cure of a "Locked-In" Patient
}

Meryl A. Severson III MD

Thomas Jefferson University

Aditya S. Pandey MD

Thomas Jefferson University

Erol Veznedaroglu MD

Thomas Jefferson University

Follow this and additional works at: https://jdc.jefferson.edu/jhnj

Part of the Neurology Commons

Let us know how access to this document benefits you

\section{Recommended Citation}

Severson III MD, Meryl A.; Pandey MD, Aditya S.; and Veznedaroglu MD, Erol (2008) "Endovascular Cure of a "Locked-In" Patient," JHN Journal: Vol. 4 : Iss. 1 , Article 3.

DOI: https://doi.org/10.29046/JHNJ.004.1.006

Available at: https://jdc.jefferson.edu/jhnj/vol4/iss1/3

This Article is brought to you for free and open access by the Jefferson Digital Commons. The Jefferson Digital Commons is a service of Thomas Jefferson University's Center for Teaching and Learning (CTL). The Commons is a showcase for Jefferson books and journals, peer-reviewed scholarly publications, unique historical collections from the University archives, and teaching tools. The Jefferson Digital Commons allows researchers and interested readers anywhere in the world to learn about and keep up to date with Jefferson scholarship. This article has been accepted for inclusion in JHN Journal by an authorized administrator of the Jefferson Digital Commons. For more information, please contact: JeffersonDigitalCommons@jefferson.edu. 


\section{Endovascular Cure of a "Locked-In" Patient}

Meryl A. Severson, III, MD, Aditya S. Pandey, MD, Erol Veznedaroglu, MD

Jefferson Hospital for Neuroscience, Philadelphia, PA

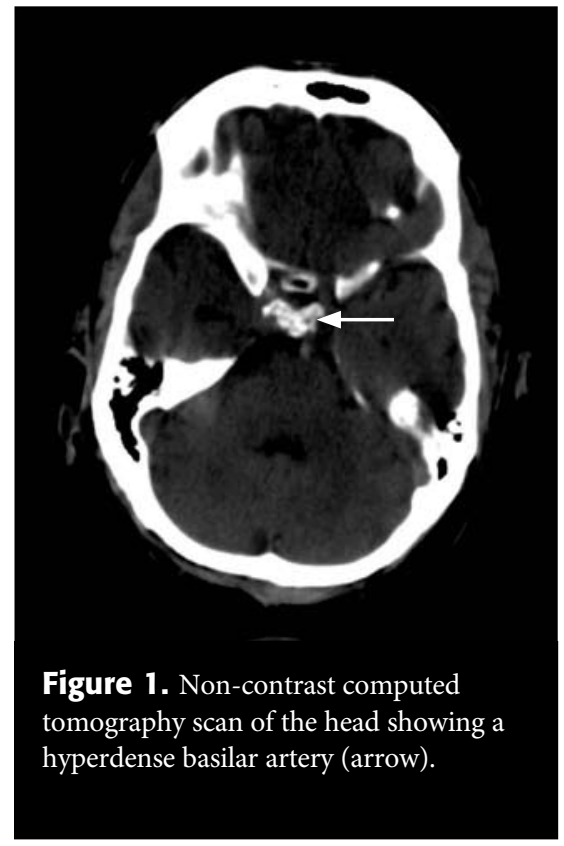

We report the case of a 60 year-old right-handed gentleman who became acutely "Locked-In" several days after a lower extremity orthopedic procedure.Heunderwentemergentendovascular treatment and had complete resolution of his neurologic findings except for mild dysarthria and dysphagia. Endovascular intervention for posterior circulation thrombosis is highly effective when patients are treated within 24 hours.

\section{Case}

FC is a 60 year-old right-handed gentleman that underwent uncomplicated total knee arthroplasty and was started on low dose warfarin therapy for deep venous thrombosis prophylaxis. On postoperative day number two the patient had an acute change in his neurologic status. A computed-tomography scan of his head was obtained showing a hyperdense basilar artery. He was emergently transferred to our institution.

On arrival the patient was lethargic but able to follow commands with eye blinks only. His pupils were equal and reactive but he only had vertical gaze. The right extremity minimally withdrew to stimulation. Computed-tomography angiogram of the head showed a dominant right vertebral artery with occlusion just distal to the posterior inferior cerebellar artery origin extending to just below the superior cerebellar arteries.

The patient was taken emergently to the Endovascular Neurosurgery Suite and the right femoral artery accessed. The right vertebral artery was selectively catheterized and digital subtraction angiography performed revealing complete occlusion of the right vertebrobasilar junction without distal runoff or PCA filling. A Hyperglide balloon was positioned at the VB junction and seven inflations were performed, revealing a focal stenosis at the junction. A Gateway 4 balloon was positioned next and inflated to six atmospheres of pressure. Subsequent angiographic runs revealed complete resolution of the thrombus and filling of both PCAs and SCAs, as well as the basilar perforators. A Wingspan $4 \times 5 \times 20$ stent was then deployed at the location of the stenosis resulting in complete resolution of the stenosis and thrombus. Additional angiographic runs showed distal occlusions bilaterally in the $\mathrm{P} 4$ segments; these were treated by placing an SL-10 microcatheter in the P4 segments and injecting 150,000 units of Urokinase on the right and 200,000 units on the left.

Post-procedurally the patient remained intubated for less than twenty-four hours. His neurologic exam improved to normal except for mild dysarthria and dysphagia and a right upper extremity drift without associated weakness. Magnetic resonance imaging of his brain revealed acute infarcts in the left pons, right occipital lobe, right dentate nucleus, both mesial temporal lobes, and the right posterolateral thalamus. He was gradually mobilized with the assistance of physical therapy/ occupational therapy and eventually discharged in good condition.

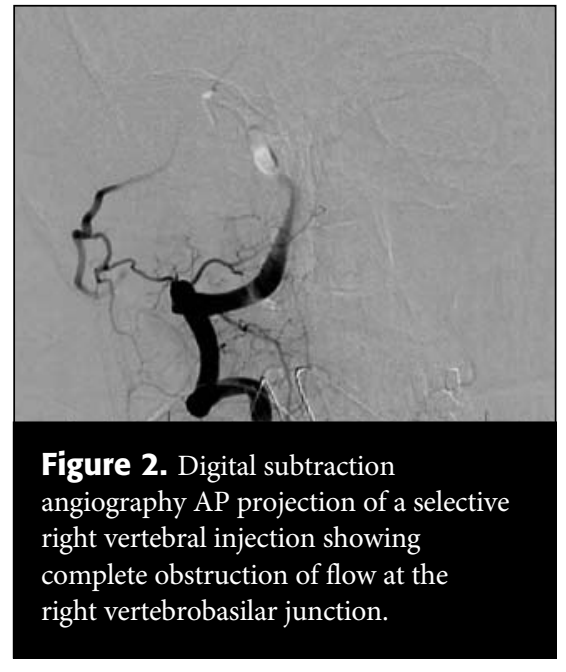

Figure 3. Digital subtraction

angiography AP projection

demonstrating inflation of the Hyperglide

balloon at the right vertebrobasilar

junction. Note the microcatheter

extending into the proximal basilar artery

and the "waist" (arrow) on the balloon

reflecting the location of the obstruction.

\section{Discussion}

Unlike anterior circulation thromboses, the time window for posterior circulation thrombosis treatment extends up to 24 hours after the ictus. Cases of complete improvement in an adolescent treated 20 hours $^{1}$ and a child almost 50 hours after symptom onset ${ }^{2}$ are 


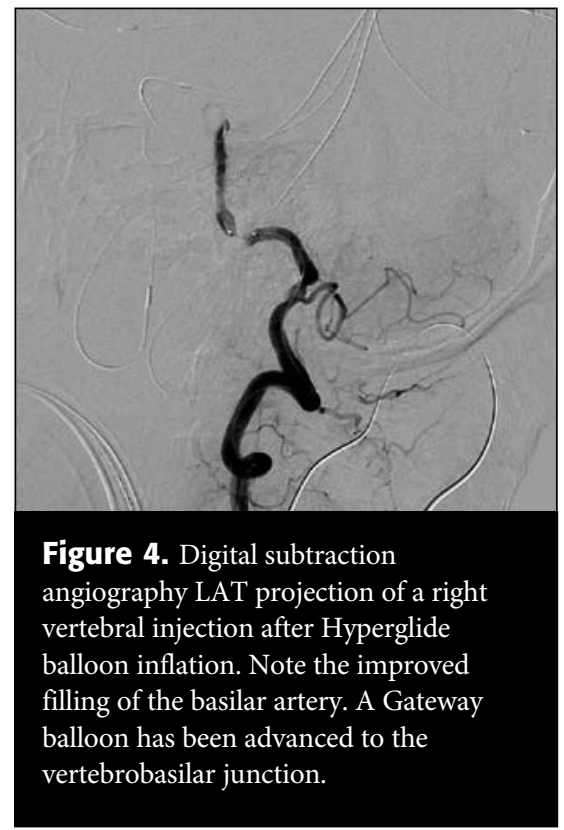

reported. However, we recommend treating up to 24 hours post-ictus only. An additional study reviewed outcome predictors for basilar artery thrombosis and found that recanalization after thrombolysis and low NIH stroke scale at admission were associated with a favorable outcome; initiating thrombolysis early after ictus as well CT evidence of a hyperdense basilar artery were positively associated with recanalization rates. ${ }^{3}$ "Locked-In" Syndrome resulting from acute basilar artery thrombosis is curable but requires the patient be quickly diagnosed and transferred expeditiously to a specialized center with a highly experienced endovascular neurosurgical team.

\section{References}

1. Kirton A, Wong JH, Mah J, Ross BC, Kennedy J, Bell K, Hill MD. Successful endovascular therapy for acute basilar thrombosis in an adolescent. Ped. 2003 Sep: 112(3 Pt 1): e248-51.

2. Grigoriadis S, Gomori JM, Grigoriadis N, Cohen JE. Clinically successful late recanalization of basilar artery occlusion in childhood: what are the odds? Case report and review of the literature. J Neurol Sci. 2007 Sep 15;260(12):256-60.

3. Arnold M, Nedeltchev K, Schroth G, Baumgartner RW, Remonda L, Loher TJ, Stepper F, Sturzenegger M, Schuknecht B, Mattle HP. Clinical and radiological predictors of recanalisation and outcome of 40 patients with acute basilar artery occlusion treated with intra-arterial thrombolysis. J Neurol Neurosurg Psychiatry. 2004 Jun; 75(6):857-62. 